\title{
Design and fabrication of a modified fish feed pelletizing machine
}

\author{
Orua Okon Antia ${ }^{1,}{ }^{*}$, Ubong Edet Assian ${ }^{1}$ and Youngson N. Ukaru ${ }^{2}$ \\ ${ }^{1}$ Department of Agricultural and Food Engineering, University of Uyo, Nigeria. \\ ${ }^{2}$ Department of Mechanical and Aerospace Engineering, University of Uyo, Nigeria.
}

Global Journal of Engineering and Technology Advances, 2021, 07(02), 001-011

Publication history: Received on 17 March 2021; revised on 28 April 2021; accepted on 01 May 2021

Article DOI: https://doi.org/10.30574/gjeta.2021.7.2.0063

\begin{abstract}
Fish feed pelletizing machine was designed and fabricated with the aim to improve on existing local pelletizers; encourage local technology and local fish farmers who may be faced with no power supply. It mainly consists of the hopper, pelletizing chamber, frame, bolts and nuts, screw conveyor, cutting mechanism, pelletizing die plate and power transmission unit with dual operation mode. Performance evaluations of the improved pelletizing machine as well as existing machine were carried out and the results showed that both machines were able to produce pellets with $8 \mathrm{~mm}$ average diameter and $10 \mathrm{~mm}$ average length. The overall mean values of pelleting capacity, specific energy consumption and efficiency of improved and the existing pelletizing machines were $1.20 \mathrm{~kg} / \mathrm{min}, 0.010 \mathrm{kWh} / \mathrm{kg}$ and $97.09 \% ; 0.89$ $\mathrm{kg} / \mathrm{min}, 0.014 \mathrm{kWh} / \mathrm{kg}$ and $75 \%$, respectively. These imply that the improved pelletizing machine could produce a ton of feeds for a 14-hour daily operation and consume approximately $10 \mathrm{kWh}$ of energy as compared to the existing pelletizing machine that would consume $14 \mathrm{kWh}$. The capacity of the improved pelletizing machine is quite better than the existing pelletizing machine. The improved pelletizing machine efficiency obtained is quite impressive as only about $2.91 \%$ of the feed mix might be lost as compared to $25 \%$ lost by the existing pelletizing machine. Therefore, the improved fish feed pelletizing machine is recommended for use by small-scale fish feed mill as the existing pelletizers have comparable higher losses couple with lower efficiency.
\end{abstract}

Keywords: Design; Fabrication; Fish; Cylindrical Pellets; Pelletizing

\section{Introduction}

Traditional method of processing fish feed is extremely strenuous; causes great discomfort to the operators and cannot predict grinding time. These result in the production of low quality feeds. The modern method is by the use of pelletizing machine. Pelletizing machine is a machine that can be used to create and extrude desired shapes of pellets from a mixture of components. In livestock, the components should have the required nutrient for their growth and development in order to meet the market requirements [1]. Also, the feed type and shape may depend on the type and age of the livestock. However, it has been observed that most livestock prefer solid and soft nutritious meals. Generally, soft capsules can easily be consumed by fish and poultry animal. Highly compressed/pelletized feed improves the nutritional value and growth of livestock, facilitates storage and transportation, saves space and extends shelf life. It also decreases feed wastage, reduces selective feeding, promotes better handling characteristics, destroys undesirable micro-organisms and increases bulk density. Other qualities added to livestock feed include complete pasteurization, improve pellet quality, increase feed utilization/ starch gelatinization and production of by-pass fat and by-pass protein $[2,3,4,5]$. Thus, pelleting machine is essential for the production of livestock feed. The pelleting machine can be classified based on (i) the type of die such as disc die and ring die pelleters (ii) the product formed such as (a) balls and agglomerate pellets using balling disc machine (b) floating feed pellets using floating feed pelleting machine, etc. The quality and quantity of pellets produced from the machine are dependent on: (i) die thickness and holes diameter; (ii)

\footnotetext{
* Corresponding author: Orua Okon Antia

Department of Agricultural and Food Engineering, University of Uyo, 520003, P. M. Box 1017, Uyo, Akwa Ibom State, Nigeria.
} 
speed of rotation for each die thickness/hole diameter combination; (iii) feed input rate; and (iv) amount of moisture in a given volume of feed. Other factors known to influence pellet quality include: (a) bulk density of the soft feed, (b) its texture, (c) proximate composition (d) prevailing ambient conditions of temperature and relative [6,7,8].

Pelletizing machines could be operated manually or electrically. In manually operated pelleting machine, the screw conveyor is moved or rotated using handle while in electrically operated machine, an electric motor (prime mover) is employed. Different pelletizing machine with different capacities and specific power consumption have been developed by many researchers in an effort to improve the efficiency of machines [9]. In spite of all these efforts, there are still limitations in terms of procurement and servicing of these machines. Others include (i) high cost of pelletizers (ii) poor design in terms of number of holes on the die and the clearance between the screw conveyor/auger and the cylinder wall (iii) high initial and maintenance costs (iv) high labour cost in securing skilled maintenance engineering staff and (v) dependency on expensive infrastructural facilities. Hence, there is need to develop a simple but modified fish pelletizing machine that could be electrically and manually operated; affordable by local farmers who may not have steady power supply, reduce drudgery and unhealthy practices in traditional method of fish feed production; and aid small scale fish farmers to produce their fish feeds and maximize profit.

\section{Material and methods}

\subsection{Materials for Construction}

The materials used in this work were hacksaw, measuring tape, hammer, spanner, filing machine, bearing, v-belt, pulley, metals, electrodes, drilling machine, and nuts and bolts.

\subsection{Materials Selection and Design Consideration}

The selection of materials was based on: (i) availability of materials in the markets; (ii) strength; (iii) cost and (iv)possession of simple mode of the operation. The following were considered in the design: (i) safe operation; (ii) power requirement; (iii) ease of operation, maintenance and repair; (iv) economic; and (v) size and durability.

\subsection{Components of the Pelletizing Machine}

The major components of the fish feed pelleting machine designed are as follows: the hopper, pelletizing chamber, frame, bolts and nuts, shaft and screw conveyor, bearing, die plate and power transmission system. Some views of the machine are presented in Figure 1 and 2.

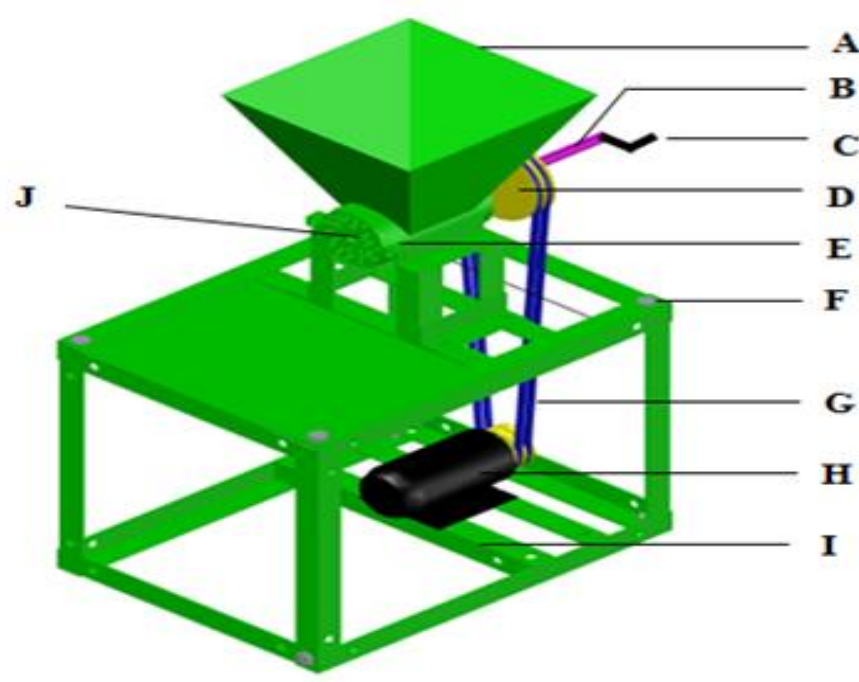

\begin{tabular}{|l|l|}
\hline Key & Parts \\
\hline A & Feed hopper \\
\hline B & Shaft \\
\hline C & Handle \\
\hline D & Driven pulley \\
\hline E & Pelletizing chamber \\
\hline F & Bolt and nut \\
\hline G & V-Belt \\
\hline H & Electric motor \\
\hline I & Frame \\
\hline J & Die plate \\
\hline
\end{tabular}

Figure 1 Isometric view of the pelletizing machine and its parts 


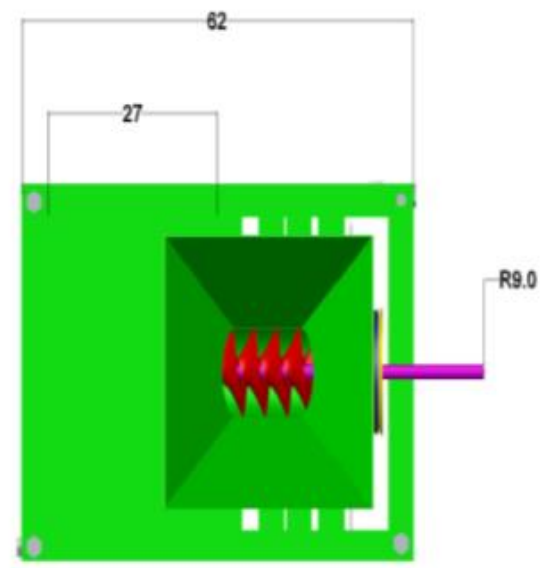

(b) Plan view

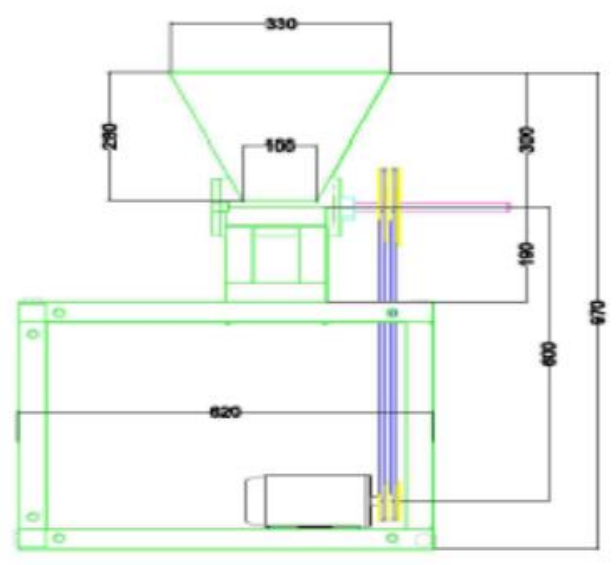

(c) Front view

Figure 2 Plan and Front view of the pelletizing machine and its parts

\subsection{Design Calculation}

Machine components design analysis and calculations were carried out using Customized Machine M236 Design and Beam Version 2.95 Software Packages in order to determine and choose materials of appropriate strength, rigidity and sizes.

\subsubsection{Hopper}

The surface area $\left(\mathrm{S}_{\mathrm{h}}\right)$ and volume of hopper $\left(\mathrm{V}_{\mathrm{h}}\right)$ are given as [10]:

$\mathrm{S}_{\mathrm{h}}=\left[2(a+b) \times \sqrt{\left(\frac{1}{2}[a+b]\right)^{2}+h^{2}}\right]$

$\mathrm{V}_{\mathrm{h}}=\frac{\mathrm{h}}{3}\left[\mathrm{a}^{2}+(\mathrm{a} \times \mathrm{b})+\mathrm{b}^{2}\right]$

Where, $\mathrm{a}=$ length of the upper section, $\mathrm{b}=$ square base and $\mathrm{h}=$ height.

\subsubsection{Pelletizing Chamber (Barrel)}

The surface area $\left(\mathrm{S}_{\mathrm{b}}\right)$ and volume $\left(\mathrm{V}_{\mathrm{b}}\right)$ are given as [11]:

$$
\begin{aligned}
& S_{h}=\pi D_{o}\left[\frac{D_{0}}{2}+L\right] \\
& V_{b}=\pi \frac{D_{i}^{2}}{4} L
\end{aligned}
$$

Where, $\mathrm{D}_{\mathrm{o}}=$ outer diameter, $\mathrm{D}_{\mathrm{i}}=$ inner diameter and $\mathrm{L}=$ length .

\subsubsection{Total Power Required for Pelletizing Process $\left(P_{t}\right)$}

The total power required for the pelletizing process is given as $[12,13]$ :

$P_{t}=\frac{\left(W_{c}+F_{a t}+W_{p}\right) V_{p}}{1000}$

Where, $\mathrm{W}_{\mathrm{c}}=$ weight of shaft, screw conveyor and cutting mechanism, $\mathrm{F}_{\mathrm{at}}=$ axial thrust by the screw conveyor, $\mathrm{W}_{\mathrm{p}}=$ weight of pulley and $\mathrm{v}_{\mathrm{p}}=$ peripheral velocity of the rotating mechanisms. 


\subsubsection{The Torque $\left(T_{m}\right)$ at Motor Pulley}

The torque at motor pulley is given as [14]:

$$
\mathrm{T}_{\mathrm{m}}=\frac{\left[\mathrm{P}_{\mathrm{s}} \times 60\right]}{\left[2 \pi \times \mathrm{N}_{1}\right]}
$$

Where, $\mathrm{P}_{\mathrm{s}}=$ power of the electric motor and $\mathrm{N}_{1}=$ speed of the electric motor.

\subsubsection{The Power Transmission System}

The belt velocity $\left(V_{1}\right)$, velocity ratio $(V R)$, nominal length of the belt $(L)$, minimum $\left(C_{\min }\right)$ and maximum $\left(C_{\text {max }}\right)$ centre distances of the pulleys were obtained as [14] :

$$
V_{1}=\frac{\left[\pi \times D_{1} \times N_{1}\right]}{60}
$$

Velocity ratio $=\frac{N_{2}}{N_{1}}=\frac{D_{1}}{D_{2}}$

Where, $\mathrm{N}_{2}=$ shaft speed, $\mathrm{D}_{2}=$ shaft pulley diameter and $\mathrm{D}_{1}=$ motor pulley diameter

$$
\begin{gathered}
\left.\mathrm{C}_{\min }=\left[0.5\left(\mathrm{D}_{2}+\mathrm{D}_{1}\right)\right]+\mathrm{D}_{1}\right] \\
\mathrm{C}_{\max }=2\left(\mathrm{D}_{2}+\mathrm{D}_{1}\right) \\
\mathrm{L}=2 \mathrm{C}+\left(\frac{\left[\pi\left(\mathrm{D}_{2}+\mathrm{D}_{1}\right)\right]}{2}\right)+\left(\frac{\left[\mathrm{D}_{2}-\mathrm{D}_{1}\right]^{2}}{4 \mathrm{C}}\right)
\end{gathered}
$$

Where, $\mathrm{C}=$ maximum center distance

\subsubsection{Angle of Inclination ( $\alpha)$, Contact Angle of the Belt $(\theta)$ and Coefficient of Friction $(\mu)$}

The angle of inclination $(\alpha)$, contact angle of the belt $(\theta)$ and coefficient of friction $(\mu)$ are expressed as [14]:

$\alpha^{o}=\arcsin \left[\frac{\mathrm{D}_{2}-\mathrm{D}_{1}}{2 \mathrm{C}}\right]$

$\Theta=\left[180^{\circ}-\left(2 \times \alpha^{\circ}\right)\right] \frac{\pi}{180}$

$\mu=\left(0.54-\left[\frac{42.5}{152.6+\mathrm{v}_{1}}\right]\right)$

Belt Tensions ( $\mathrm{T}_{1}$ and $\left.\mathrm{T}_{2}\right)$ and Power Transmitted by the Belt $\left(\mathrm{P}_{\mathrm{b}}\right)$

The belt tensions $\left(\mathrm{T}_{1}\right.$ and $\left.\mathrm{T}_{2}\right)$ and power transmitted by the belt $\left(\mathrm{P}_{\mathrm{b}}\right)$ were calculated as [14]:

$$
\begin{aligned}
\mathrm{T}_{2} & =\left(\frac{\mathrm{T}_{\mathrm{m}}}{0.5 \mathrm{D}_{1}}\right) \times \frac{1}{\left(\mathrm{e}^{\left[\mu \cdot \Theta \operatorname{cosec} \beta^{\circ}\right]}\right)-1} \\
\mathrm{~T}_{1} & =\left(\frac{\mathrm{T}_{\mathrm{m}}}{0.5 \mathrm{D}_{1}}\right)-\mathrm{T}_{2} \\
\mathrm{P}_{\mathrm{b}} & =\left(\mathrm{T}_{1}-\mathrm{T}_{2}\right) \times \mathrm{V}_{1}
\end{aligned}
$$

Where, $\mathrm{T}_{\mathrm{m}}=$ torque at motor pulley, $\mathrm{T}_{2}=$ tension on the slack side of the belt, $\mathrm{T}_{1}=$ tension on the tight side of the belt and $\mathrm{P}_{\mathrm{b}}=$ power transmitted by the belt.

\subsubsection{Shaft Design}

The shaft was designed based on what it would be subjected to, i.e., the combined twisting and bending moments. Distances from the point where moment was taken, vertical and horizontal loads were manipulated into Beam Version Software 2.95 to obtain vertical and horizontal loading diagrams. 
The resultant bending moment $\left(M_{R}\right)$, equivalent twisting moment $\left(T_{e}\right)$ and shaft diameter $\left(d_{s}\right)$ were calculated as [14]:

$\mathrm{M}_{\mathrm{R}}=\sqrt{\left(\mathrm{MBM}_{\mathrm{V}}\right)^{2}+\left(\mathrm{MBM}_{\mathrm{H}}\right)^{2}}$

where, $\mathrm{MBM}_{\mathrm{V}}=$ vertical bending moment and $\mathrm{MBM}_{\mathrm{H}}=$ horizontal bending moment.

$\mathrm{T}_{\mathrm{e}}=\sqrt{\left(\mathrm{M}_{\mathrm{R}}\right)^{2}+\left(\mathrm{T}_{\mathrm{m}}\right)^{2}}$

$\mathrm{d}_{\mathrm{s}}=\left[\frac{16 \mathrm{~T}_{\mathrm{e}}}{\tau \pi}\right]^{1 / 3}$

\subsubsection{Key and Keyway Design}

Key width $\left(\mathrm{W}_{\mathrm{k}}\right)$, key length $\left(\mathrm{L}_{\mathrm{k}}\right)$ and key thickness $\left(\mathrm{t}_{\mathrm{k}}\right)$ were obtained as [14]:

$\mathrm{W}_{\mathrm{k}}=\frac{\mathrm{d}_{\mathrm{s}}}{4}$

$\mathrm{L}_{\mathrm{k}}=\frac{2 \times \mathrm{T} \times 1000}{\mathrm{~W}_{\mathrm{k}} \tau \mathrm{d}_{\mathrm{s}}}$

$\mathrm{t}_{\mathrm{k}}=\frac{4 \times \mathrm{T} \times 1000}{\mathrm{~L}_{\mathrm{k}} \mathrm{d}_{\mathrm{s}} \sigma_{\mathrm{c}}}$

Where, $\sigma_{\mathrm{c}}=$ key crushing stress and $\mathrm{T}=$ torque transmitted by the shaft.

\subsubsection{Bearing Selection for Shaft}

The equivalent dynamic load (P), on the system, the nominal rating life of the bearing (L), the full bearing life in working hours $\left(\mathrm{L}_{\mathrm{h}}\right)$ and reliability $(\mathrm{R})$ were calculated as $[15,14]$ :

$\mathrm{P}=\left[\mathrm{X} \cdot \mathrm{V} \cdot \mathrm{F}_{\mathrm{r}}\right]+\left[\mathrm{Y} \cdot \mathrm{F}_{\mathrm{a}}\right]$

$\mathrm{L}=\left[\frac{\mathrm{C}}{\mathrm{P}}\right]^{\mathrm{k}} \times 10^{6}$ revolutions

$\mathrm{L}_{(\mathrm{h})}=\frac{5 \times \mathrm{L}}{60 \mathrm{~N}_{2}} \quad[$ hours $]$

[ Note: If $\mathrm{L}_{\mathrm{h}}>4000$ hours, the bearing is selected]

$$
\log _{e}\left[\frac{1}{R}\right]=\left[\frac{L}{a^{*}}\right]^{b^{*}}
$$

Where, $\mathrm{F}_{\mathrm{r}}=$ radial load, $\mathrm{F}_{\mathrm{a}}=$ axial load, $\mathrm{C}=$ basic dynamic load rating, $\mathrm{k}=$ life exponent for ball bearing, $\mathrm{N}_{2}=$ shaft speed, $\mathrm{Y}=$ axial load factor, $\mathrm{X}=$ radial load factor, $\mathrm{V}=$ bearing type, $\mathrm{a}^{*}$ and $\mathrm{b}^{*}$ are constants.

\subsubsection{Design of the Frames and Bolts}

The frame and bolts designs were obtained based on the consideration to the shear stress on the machine $[16,17,18]$ as:

$\mathrm{d}_{\mathrm{b}}=\sqrt{\frac{4 \times \mathrm{W}_{\mathrm{tmax}}}{\pi \mathrm{S}_{\mathrm{e}}}}$

Where, $\mathrm{d}_{\mathrm{b}}=$ bolt diameter, $\mathrm{W}_{\mathrm{t} \text { max }}=$ assumed maximum total weight of the machine/loads and $\mathrm{S}_{\mathrm{e}}=$ allowable endurance stress of mild steel.

\subsubsection{Die Design}

The effective die area $\left(A_{c}\right)$, die output area $\left(A_{o}\right)$ and axial thrust $\left(F_{\text {at }}\right)$ required to extrude the feed mix were given as [14]: 


$$
\begin{aligned}
& \mathrm{A}_{\mathrm{c}}=\frac{\pi}{4}\left(\mathrm{~d}_{\mathrm{d}}^{2}-\mathrm{d}_{\mathrm{s}}^{2}\right) \\
& \mathrm{A}_{\mathrm{o}}=\frac{\pi}{4} \times \mathrm{d}_{\mathrm{h}}^{2} \times \mathrm{N}_{\mathrm{h}} \\
& \mathrm{F}_{\mathrm{at}}=\mathrm{P}_{\mathrm{e}} \times\left(\mathrm{A}_{\mathrm{c}}-\mathrm{A}_{\mathrm{o}}\right)
\end{aligned}
$$

Where, $N_{h}=$ number of die holes, $d_{h}=$ each die diameter, $d_{d}=$ pellet diameter and $P_{e}=$ extruding pressure.

\subsection{Cost of Materials for Machine Fabrication}

The bill of engineering materials is presented in Table1.

Table 1 Bill of Engineering Materials

\begin{tabular}{|l|l|l|}
\hline S/N & Description & Total Price (N) \\
\hline 1 & Angle bars & $15,000.00$ \\
\hline 2 & Bolts and nuts & $1,000.00$ \\
\hline 3 & Metal plate & $7,000.00$ \\
\hline 4 & Ball bearing & $1,500.00$ \\
\hline 5 & Shaft with screw conveyor & $1,500.00$ \\
\hline 6 & Electric motor & $35,000.00$ \\
\hline 7 & Belt & 800.00 \\
\hline 8 & Pulley & 700.00 \\
\hline 9 & Labour/Painting & $18,000.00$ \\
\hline & Total & $80,500.00$ \\
\hline
\end{tabular}

\subsection{Mode of Operation of Pelletizing Machine}

The dough (feed mix) is introduced into the hopper. The gate allows the feed mix to get down by gravity into a $0.005 \mathrm{~m}$ thick cylindrical steel pelletizing chamber (barrel) for caking of the feed. The feed pelletizing machine is powered by an electric motor which rotates the shaft carrying the screw conveyor by the aid of pulley and belt system. The rotation of the shaft is such that the screw conveyor moves the dough towards the die where a three- metal blade (cutting mechanism) fitted on the shaft moves at the speed of the shaft and cuts the feed as it passes through the die where the pellets are formed.

\subsection{Performance Evaluation of the Improved Pelletizing Machine}

$2 \mathrm{~kg}$ feed mix was weighed and introduced into the pelletizing machine. The time for the feed mix to completely form the products (pellets) when it was operated, was noted. The length and mass of pellets produced were also measured using vernier calipers and electronic weighing balance. The test was replicated and the average values calculated. The procedure was repeated for 2.5, 3.0, 3.5, 4.0, 4.5 and $5.0 \mathrm{~kg}$ feed mixes. The following parameters: pelleting capacity, specific energy consumption and machine efficiency were used to assess the performance of the pelletizing machine as given in equations (32) to (34).

$$
\begin{aligned}
& \mathrm{PC}=\frac{\text { Mass of pellets produced }(\mathrm{Kg})}{\text { Time taken }(\mathrm{min})} \\
& \mathrm{SEC}=\frac{\text { Power of electric motor }(\mathrm{kW}) \times \text { time taken }(\mathrm{h})}{\text { Mass of pellets produced }(\mathrm{kg})} \\
& \eta=\frac{\text { Mass of pellets produced }(\mathrm{kg})}{\text { Mass of feed mix }(\mathrm{kg})} \times 100
\end{aligned}
$$

Where, $\mathrm{PC}=$ pelleting capacity $(\mathrm{kg} / \mathrm{min}), \mathrm{SEC}=$ specific energy consumption $(\mathrm{kWh} / \mathrm{kg})$ and $\eta=$ machine efficiency $(\%)$. The procedure was repeated using the existing pelletizing machine. 


\section{Results and discussion}

The pelletizing machine specifications based on design calculation are presented as follows:

\subsection{Hopper}

- $\quad$ Length of upper section $(\mathrm{a})=0.33 \mathrm{~m}$

- Square base (b) $\quad=0.10 \mathrm{~m}$

- Height (h) $\quad=0.28 \mathrm{~m}$

- Surface area $\left(\mathrm{S}_{\mathrm{h}}\right) \quad=0.26 \mathrm{~m}^{2}$

- Volume $\left(\mathrm{V}_{\mathrm{h}}\right) \quad=0.014 \mathrm{~m}^{3}$

\subsection{Pelletizing chamber}

- $\quad$ Outer diameter $\left(\mathrm{D}_{\mathrm{o}}\right)=0.110 \mathrm{~m}$

- Inner diameter $\left(\mathrm{D}_{\mathrm{i}}\right)=0.100 \mathrm{~m}$

- Length (L) $\quad=0.180 \mathrm{~m}$

- Surface area $\left(\mathrm{S}_{\mathrm{b}}\right)=0.081 \mathrm{~m}^{2}$

- Volume $\left(\mathrm{V}_{\mathrm{b}}\right) \quad=0.0014 \mathrm{~m}^{3}$

\subsection{Total power required for pelleting process}

- Axial thrust by the screw conveyor $\left(\mathrm{F}_{\mathrm{at}}\right)=65 \mathrm{~N}$

- Weight of shaft, screw conveyor and cutting mechanism $\left(\mathrm{W}_{\mathrm{c}}\right)=25 \mathrm{~N}$

- Peripheral velocity of the rotating mechanisms $\left(V_{p}\right)=6 \mathrm{~m} / \mathrm{s}$

- Dimension of each blade from the centre of the shaft $=4 \mathrm{~mm}$ by $5 \mathrm{~mm}$ by $50 \mathrm{~mm}$

- The total power required for pelletizing process $\left(\mathrm{P}_{\mathrm{t}}\right)=0.624 \mathrm{~kW}$

- Electric motor: Viking single-phase, $1.0 \mathrm{Hp}(0.745 \mathrm{~kW}), 1400 \mathrm{rpm}$

\subsection{Torque $\left(T_{m}\right)$ at motor pulley}

- Torque $\left(\mathrm{T}_{\mathrm{m}}\right)=5.08 \mathrm{Nm}$

\subsection{Power transmission system}

- $\quad$ Belt type $=$ " $A$ "

- Motor pulley diameter $\left(\mathrm{D}_{1}\right)=0.065 \mathrm{~m}$

- Shaft pulley diameter $\left(\mathrm{D}_{2}\right)=0.140 \mathrm{~m}$

- Belt velocity $\left(\mathrm{V}_{1}\right) \quad=4.77 \mathrm{~m} / \mathrm{s}$

- Shaft speed $\left(\mathrm{N}_{2}\right) \quad=650 \mathrm{rpm}$

- Velocity ratio (VR) $\quad=0.03$

- Minimum centre distance $\left(\mathrm{C}_{\min }\right)=0.168 \mathrm{~m}$

- Maximum centre distance $\left(C_{\max }\right)=0.410 \mathrm{~m}$

- The nominal length of the belt $(\mathrm{L})=1.143 \mathrm{~m}$

- Angle of contact or wrap $(\theta)=2.96 \mathrm{rad}$

- Angle of inclination $(\alpha) \quad=5.25^{\circ}$

- Coefficient of friction $(\mu) \quad=0.44$ (for leather belt on cast iron pulley)

\subsection{Belt tension and power transmitted by the belt}

- Tension on the tight side of the belt $\left(\mathrm{T}_{1}\right)=154.6 \mathrm{~N}$

- Tension on the slack side of the belt $\left(\mathrm{T}_{2}\right)=1.79 \mathrm{~N}$

- Angle of groove $(\beta)$ for " $\mathrm{A}$ "-type $\mathrm{V}$-belt $=17^{0}$

- The power transmitted by the belt $\left(\mathrm{P}_{\mathrm{b}}\right)=0.728 \mathrm{~kW}$

\subsection{Shaft design}

The shaft loading diagram obtained is presented in Figures $3-5$ with other parameters as: 


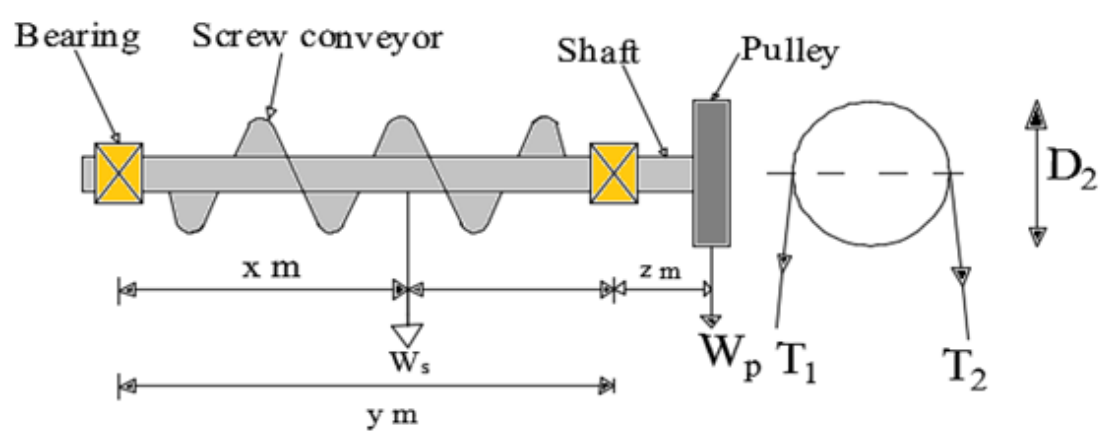

Figure 32 -D view of shaft with double groove pulley, screw conveyor and supported by 2 bearings

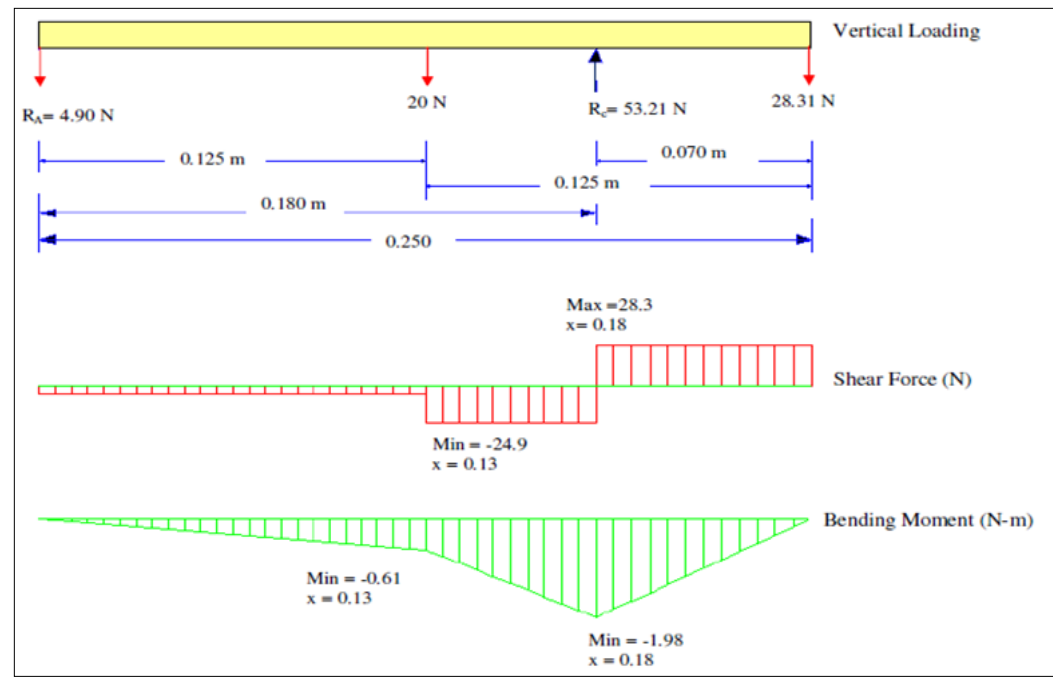

Figure 4 Vertical loading on the shaft

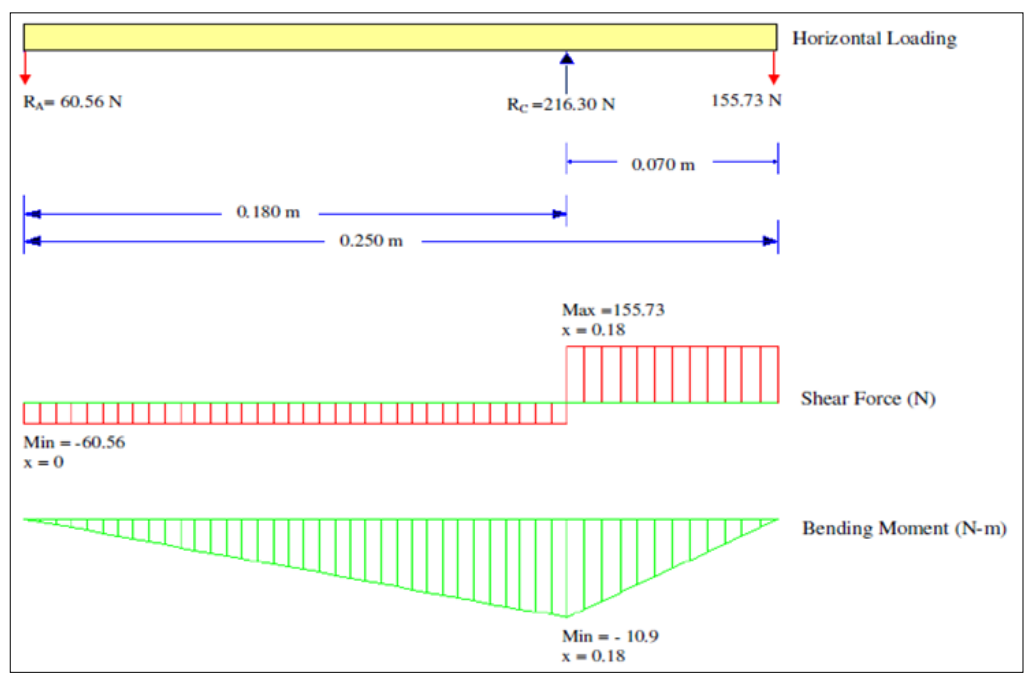

Figure 5 Horizontal loading on the shaft

\subsection{Note}

- For vertical loading, the reaction at $\mathrm{R}_{\mathrm{A}}=53.21 \mathrm{~N}$ and $\mathrm{R}_{\mathrm{c}}=-4.90 \mathrm{~N}$

- For horizontal loading, the reaction at $R_{A}=216.30 \mathrm{~N}$ and $\mathrm{R}_{\mathrm{c}}=-60.56 \mathrm{~N}$

- Maximum vertical bending moment $\left(\mathrm{MBM}_{\mathrm{V}}\right)=-1.98 \mathrm{~N}-\mathrm{m}$

- Maximum horizontal bending moment $\mathrm{MBM}_{\mathrm{H}}=-10.90 \mathrm{~N}-\mathrm{m}$

- (v) Resultant bending moment $\left(\mathrm{M}_{\mathrm{R}}\right) \quad=11.08 \mathrm{~N}-\mathrm{m}$

- (vi) Equivalent twisting moment $\left(\mathrm{T}_{\mathrm{e}}\right) \quad=12.19 \mathrm{~N}-\mathrm{m}$ 
Shaft diameter $\left(d_{s}\right)=11.1 \mathrm{~mm}$ [12 mm selected based on the strength, rigidity, stiffness and allowable shear stress $(\tau)$ of $42 \mathrm{~N} / \mathrm{mm} 2]$

\subsection{Key and keyway Design}

- $\quad$ Key width $\left(\mathrm{W}_{\mathrm{k}}\right)=3.0 \mathrm{~mm}$

- $\quad$ Key length $\left(\mathrm{L}_{\mathrm{k}}\right)=7.3 \mathrm{~mm}$

- $\quad$ (iii)Key thickness $\left(\mathrm{t}_{\mathrm{k}}\right)=2.8 \mathrm{~mm}$

Note that the values were obtained based on key crushing stress $\left.\left(\sigma_{\mathrm{c}}\right)=84 \mathrm{~N} / \mathrm{mm}^{2}\right)$ and torque transmitted by the shaft $(\mathrm{T})=5.08 \mathrm{~N}-\mathrm{m}$.

\subsection{Bearing selection for shaft}

- The equivalent dynamic load $(P)=0.297 \mathrm{kN}$ (using radial load factor, $\mathrm{X}=0.56$, bearing type $(\mathrm{V}=1$, for all types of bearing when the inner race is rotating), radial load, $\mathrm{F}_{\mathrm{r}}=0.04831 \mathrm{kN}$, axial load factor, $\mathrm{Y}=1.73$ and axial load, $\mathrm{F}_{\mathrm{a}}=0.15573 \mathrm{kN}$

- The nominal rating life of the bearing $(\mathrm{L})=6.03 \times 10^{9}$ revs (using basic dynamic load rating, $\mathrm{C}=5.4 \mathrm{kN}$ and life exponent, $\mathrm{k}=3$, for ball bearings)

- The full bearing life in working hours $\left(\mathrm{L}_{\mathrm{h}}\right)=772549$ hours [Hence,bearing as $\mathrm{L}_{\mathrm{h}}>4000$ hours, and so double row deep groove ball bearing with the code S6204 W303B was selected to support the loads on the shaft].

- The reliability (R) of $100 \%$ (Using the constants $\left[\mathrm{a}^{*}=6.84\right.$ and $\left.\mathrm{b}^{*}=1.17\right]$ )

\subsection{Design of frames and bolts}

- Maximum total weight of the machine/loads $\left(\mathrm{W}_{\mathrm{t} \text {.max }}\right)=0.4 \mathrm{kN}$

- Bolt diameter $\left(\mathrm{d}_{\mathrm{b}}\right)=2.17 \mathrm{~mm}$ [Using allowable endurance stress of mild steel $\left(\mathrm{S}_{\mathrm{e}}\right)$ as $107.696 \times 10^{3} \mathrm{kN} / \mathrm{m}^{2}$ ].

\subsection{Die design}

- $\quad$ Pellet diameter $\left(\mathrm{d}_{\mathrm{d}}\right)=130 \mathrm{~mm}$

- Pellet thickness $(\mathrm{t})=5 \mathrm{~mm}$

- Number of die holes $\left(\mathrm{N}_{\mathrm{h}}\right)=25$

- Die hole diameter $\left(\mathrm{d}_{\mathrm{h}}\right)=8 \mathrm{~mm}$

- $\quad$ Effective die area $\left(\mathrm{A}_{\mathrm{c}}\right)=52647.35 \mathrm{~mm}^{2}$

- $\quad$ Die output area $\left(\mathrm{A}_{\mathrm{o}}\right)=5027.20 \mathrm{~mm}^{2}$

- $\quad$ Axial thrust $\left(\mathrm{F}_{\mathrm{at}}\right)=65 \mathrm{~N}$

- $\quad$ Extruding pressure $\left(\mathrm{P}_{\mathrm{e}}\right)=1.36 \times 10^{-3} \mathrm{~N} / \mathrm{mm}^{2}$

The fabricated pelletizing machine performance evaluation is presented in Table 2 .

Table 2 Mean mass of feed mix, pellets produced, pelleting time and capacity, specific energy consumption and efficiency of improved machine

\begin{tabular}{|c|c|c|c|c|c|c|c|}
\hline$S / N$ & $\begin{array}{l}\text { Mass of } \\
\text { Feed Mix } \\
{\left[M_{f}\right](k g)}\end{array}$ & $\begin{array}{l}\text { Mass of Pellets } \\
\text { Produced }\left[M_{p}\right] \\
(\mathrm{kg})\end{array}$ & $\begin{array}{l}\text { Length of } \\
\text { Pellets } \\
\text { Produced }[L] \\
(\mathrm{mm})\end{array}$ & $\begin{array}{l}\text { Pelleting } \\
\text { Time [t] } \\
\text { (min) }\end{array}$ & $\begin{array}{l}\text { Pelleting } \\
\text { Capacity [PC] } \\
\text { (kg/min) }\end{array}$ & SEC & $\begin{array}{l}\text { Machine } \\
\text { Efficiency } \\
\text { [n] (\%) }\end{array}$ \\
\hline 1 & 2.00 & 1.93 & 10.2 & 1.5 & 1.29 & 0.0097 & 96.5 \\
\hline 2 & 2.50 & 2.43 & 10.3 & 2.0 & 1.22 & 0.0102 & 97.2 \\
\hline 3 & 3.00 & 2.96 & 9.8 & 2.4 & 1.23 & 0.0101 & 98.7 \\
\hline 4 & 3.50 & 3.34 & 10.2 & 3.0 & 1.11 & 0.0112 & 95.4 \\
\hline 5 & 4.00 & 3.83 & 9.9 & 3.3 & 1.16 & 0.0107 & 95.8 \\
\hline 6 & 4.50 & 4.45 & 10.1 & 3.7 & 1.20 & 0.0103 & 98.9 \\
\hline \multirow[t]{2}{*}{7} & 5.00 & 4.86 & 9.9 & 4.0 & 1.22 & 0.0102 & 97.2 \\
\hline & & Overall Mean & 10.03 & & 1.20 & 0.0103 & 97.09 \\
\hline
\end{tabular}


The existing machine performance evaluation was also carried and is presented in Table 3.

Table 3 Mean mass of feed mix, pellets produced, pelleting time and capacity, specific energy consumption and efficiency of the existing machine

\begin{tabular}{|c|c|c|c|c|c|c|c|}
\hline $\mathbf{S} / \mathbf{N}$ & $\begin{array}{l}\text { Mass of } \\
\text { Feed Mix } \\
{\left[M_{f}\right](\mathbf{k g})}\end{array}$ & $\begin{array}{l}\text { Mass of Pellets } \\
\text { Produced }\left[M_{p}\right] \\
(\mathrm{kg})\end{array}$ & $\begin{array}{l}\text { Length of } \\
\text { Pellets } \\
\text { Produced }[L] \\
(\mathrm{mm})\end{array}$ & $\begin{array}{l}\text { Pelleting } \\
\text { Time [t] } \\
\text { (min) }\end{array}$ & $\begin{array}{l}\text { Pelleting } \\
\text { Capacity } \\
{[\mathrm{PC}]} \\
(\mathrm{kg} / \mathrm{min})\end{array}$ & SEC & $\begin{array}{l}\text { Machine } \\
\text { Efficiency } \\
\text { [n] (\%) }\end{array}$ \\
\hline 1 & 0.50 & 0.38 & 8.6 & 0.36 & 1.04 & 0.012 & 75 \\
\hline 2 & 1.00 & 0.84 & 7.9 & 0.85 & 0.99 & 0.013 & 84 \\
\hline 3 & 2.50 & 1.62 & 9.0 & 2.50 & 0.65 & 0.019 & 65 \\
\hline 4 & 4.00 & 3.25 & 11.2 & 3.50 & 0.93 & 0.013 & 81 \\
\hline \multirow[t]{2}{*}{5} & 4.67 & 3.31 & 8.3 & 4.00 & 0.83 & 0.015 & 71 \\
\hline & & Overall Mean & 9.0 & - & 0.89 & 0.014 & 75 \\
\hline
\end{tabular}

A comparative analysis of the existing and improved pelleting machine was based on the fact that the same feed mix, diameter of die hole and power supplied. Both pelletizing machines were able to produce pellets of $8 \mathrm{~mm}$ average diameter. The improved pelletizing machine produced pellets of $10 \mathrm{~mm}$ average length as compared to $9 \mathrm{~mm}$ length produced by the existing machine. The overall mean values of pelleting capacity, specific energy consumption and efficiency of improved and the existing pelletizing machines were $1.20 \mathrm{~kg} / \mathrm{min}, 0.010 \mathrm{kWh} / \mathrm{kg}$ and $97.09 \% ; 0.89 \mathrm{~kg} / \mathrm{min}$, $0.014 \mathrm{kWh} / \mathrm{kg}$ and $75 \%$, respectively. These imply that the improved pelletizing machine could produce a ton of feeds for a 14-hour daily operation and consume approximately $10 \mathrm{kWh}$ of energy as compared to the existing pelletizing machine that would consume $14 \mathrm{kWh}$. The capacity of the improved pelletizing machine is quite better than the existing pelletizing machine. The improved pelletizing machine efficiency obtained is quite impressive as only about $2.91 \%$ of the feed mix might be lost as compared to $25 \%$ lost by the existing pelletizing machine. Therefore, the improved fish feed pelletizing machine is recommended for use by small-scale fish feed mill.

\section{Conclusion}

The improved fish feed pelletizing machine developed was able to convert formulated fish feed dough into pellets with efficiency of $97.09 \%$ as compared to the existing pelletizing machine of $75 \%$. With the improved fish feed pelletizing machine capacity of $1.20 \mathrm{~kg} / \mathrm{min}$, the machine can produce a ton of feeds for a 14-hour daily operation making it more efficient for small-scale fish feed mill.

\section{Compliance with ethical standards}

\section{Disclosure of conflict of interest}

There is no conflict of interest for this manuscript.

\section{References}

[1] Mc-Donald P. Animal Nutrition. Longman, London. 1995; 69 - 96.

[2] Kumar D. Fish Culture in Undrinkable Ponds: A Manual for Extrusion, FAO Fisheries Technical Paper. 1992; 31 35.

[3] Kabuage LW, Mbugua PN, Mitaru BN, Ngatia TA. Effect of Steam Pelleting and Inclusion of Molasses in Amaranth Diets on Broiler Chicken Performance, Carcass Composition and Histopathology of some Internal Organs: 2010. Retrieved. 9 January 2005.

[4] Salmatec Manufacturing Co. Ltd. SALMATEC for the Whole World of Pelleting. 2000.

[5] Food and Agricultural Organization. Boosting Production, Processing and Marketing of Fisheries, Food and Agriculture Organization, Rome, Italy. 2003.

[6] Theresa KK, David TO. Development of A Revolving Die and Roller Fish Feed Pelletizer, International Journal of Engineering Innovation \& Research. 2013; 2(1): 2277 - 5668.

[7] Faborode MO. Design, Fabrication and Testing of a Cassava pelletizer. Res. Agr. Eng. 2014; 60: 148-154. 
[8] Food and Agricultural Organization [FAO]. Aquaculture Development and Coordination Programme, Fish Feed Technology. 2008.

[9] Groesbeck C N, McKinney L J, DeRouchey J M, Tokach M D, Goodband R D, Nelssen J M, Dritz S S, Behnke K C. Effect of Glycerol on Pellet Mill Production Efficiency, Swine Day 2007, Kansas State University. November 2007: 200209.

[10] Keisan Casio. Useful Calculators. 2020.

[11] Dennis GZ, Michael RC. Advance Engineering Mathematics, Volume 1. Jones and Bartlett Learning: Technology and Engineering. 2006; 929.

[12] Oke P O. Development and Performance Evaluation of Indigenous Palm Kernel Dual Processing Machine. Journal of Engineering and Applied Sciences (JEAS). 2007; 2(4): 701-705.

[13] Fellows P. Food Processing Technology (Principles and Practices). Second Edition, WoodHead Publishing Limited, Cambridge, English. 2000.

[14] Khurmi RS, Gupta JK. A Textbook of Machine Design. Eurasia Publishing House (PVT.) Ltd, Ram Nagar: New Delhi. 2012; 110: 055.

[15] Harris TA, Rotzalas MN. Essential Concept of Bearing Technology, Rolling Bearing Analysis ( Fifth Edition), CRC Press, Taylor and Francis Group: New York. 2006.

[16] Black PH, Adams OE. Machine Design 6th Edition. McGraw-Hill Kogakusha Ltd. Tokyo. 2000; $277-278$.

[17] Shigley JE, Mischke CR. Mechanical Engineering Designs (in S.I units) (6th Edition). Tata McGraw-Hill Publishing Company: New Delhi. 2006; 156-158.

[18] Etoamaihe U J, Iwe M 0). Development and Performance Evaluation of a Reciprocating Motion Cassava Shredder. International Journal of Engineering and Science (IJES). 2014; 3(4): 06 - 15. 